\title{
ANÁLISE DAS TENSÕES DE ALÍVIOS EM BLOCOS PARA ROCHAS ORNAMENTAIS: SÃO MARCOS E DOS PEGMATÓIDES GOLDEN, EXOTIC E CAPUCCINO
}

\author{
Alfredo César Vale de Araújo ' \\ Marcilho José Dias Vieira ${ }^{2}$ \\ Evenildo Bezerra de Melo ${ }^{2}$ \\ Felisbela Maria de Oliveira' \\ Márcio Luiz de Siqueira Campos Barros ${ }^{2}$
}

\section{Resumo}

Muitos corpos rochosos superficiais apresentam elevadas componentes horizontais de tensões naturais. A concentração destas tensões em decorrência da lavra de rochas ornamentais pode causar a propagação de fraturas em bancadas e pranchas, comprometendo a recuperação da reserva. Portanto esta análise é uma importante ferramenta a ser aplicada ao planejamento de lavra de rocha ornamental. O mapeamento das descontinuidades, as distribuições das tensões, os marcadores de deformação (Sigmóides, Boudins e fraturas de Riedel) devem ser considerados no estudo das fraturas ocasionadas na exploração de rochas ornamentais pelo alívio gerado, dependendo do estado do maciço: confinado ou aflorante. Este artigo estuda os marcadores de deformação, e das fraturas de alívio, nas jazidas de rochas ornamentais Preto São Marcos, Golden, Exotic, e Cappuccino localizadas, respectivamente nos municípios de Casserengue e Santo Antônio do Seridó, na Paraíba. Para a análise das tensões e deformações, conclui-se que na produção de rochas ornamentais é determinante que as frequências de fraturas sejam inferiores a $1 / \mathrm{m}$ para viabilizar a produção de blocos após o desmonte da prancha.

Palavras-chave: Maciços; Tensões; Aflorante; Confinado.

\section{ANALYSIS OF STRESS RELIEF BLOCK FOR ORNAMENTAL ROCKS: SAN MARCOS AND GOLDEN PEGMATOID, EXOTIC AND CAPUCCINO}

\begin{abstract}
Several superficial rocky massif present high horizontal components of natural strains. The concentration of these tensions as a result of the mining of ornamental rocks can cause the spread of fractures in the stands and boards, jeopardizing the recovery of the reserve. Therefore this analysis is an important tool to be applied to the planning of ornamental rock mining. Mapping of discontinuities, distribution of stress, deformation markers (sigmoid, Boudins and Riedel fractures) should be considered in the study of fractures caused in the exploration of ornamental rocks by the relief generated, depending on the rocky massif state: confined or outcropping. This paper studies the deformation and relief fractures markers in the deposits of ornamental rocks St. Mark Black, Golden, Exotic, and Cappuccino located respectively in the municipalities of Casserengue and Santo Antonio of Seridó, Paraíba. For the analysis of stresses and deformations, it is concluded that in the production of ornamental rocks it is determinant that the frequency of fractures are less than $\mathrm{I} / \mathrm{m}$ to facilitate the production of blocks after the dismantling of the board.
\end{abstract}

Keywords: Massif; Tension; Outcropping; Confined.

'Departamento de Geologia, Universidade Federal de Pernambuco - UFPE, Recife, PE, Brasil. E-mail: cesarvale_araujo@hotmail.com

${ }^{2}$ Departamento de Engenharia de Minas, Universidade Federal de Pernambuco - UFPE, Recife, PE, Brasil. 


\section{INTRODUÇÃO}

As várias forças atuantes no interior da crosta terrestre causam perturbações no maciço rochoso, fato observado no terreno onde as rochas originalmente formadas a grandes profundidades hoje afloram, mostrando terem sido deformadas através dos tempos geológicos. Nesses maciços devem ser buscados os marcadores de deformação característicos de estágio frágil, dúctil e rúptil [I]. A força externa atuante em um maciço rochoso resulta em marcadores de deformação tais como sigmóides preservados ou, às vezes, rompidos (rods), fraturas de alívio, de distensão ou de cisalhamento (par de Riedel - que pode evoluir para falhas) e boudin, elementos estruturais caracterizados por deformações ocorridas nos maciços e, portanto, marcadores do estágio alcançado pelo evento deformador. Os movimentos podem ter máxima componente horizontal, denominada direcional ou transcorrente, podendo ser sinistrógiros (anti-horários ou sinistros) ou levógiros (horários ou dextrais). As fraturas de Riedel, que constituem um par conjugado, formando ângulo de $60^{\circ}$, resultam de esforço compressivo atuante na bissetriz do ângulo agudo supracitado [2]. Podem ser transformadas em falhas e movimento de camadas, caracterizando o estágio rúptil da deformação. Muitas vezes, na Natureza, se observa esse par conjugado associado com superfícies de cisalhamento, nomeada $\mathrm{C}$, e foliação da rocha, denominada de $\mathrm{S}$. Exemplo mais acessível à observação são os experimentos em que se testam corpos de prova para determinação do limite de ruptura, oportunidade em que as fraturas, tipo par de Riedel, evoluem para falhas justamente quando o corpo de prova se rompe. $O$ ângulo do referido par, exibe uma forma em $\mathrm{V}$, o que facilita a sua distinção, inclusive quando associado com superfície de cisalhamento e com sigmóide como na Figura I, ou quando não há sigmóide como apresentado na Figura 2. Observe-se que quando há sigmóide rompido, também conhecido como Rod, mostrado na Figura I, ou quando há boudin, sua presença é mais frequente e melhor observada no segundo caso, pois melhor se caracteriza o estágio de deformação rúptil [2].

Boudin é a forma resultante do processo de boudinage pelo qual uma rocha ou mineral mais competente do que a encaixante adquire um formato lenticular, cujo alongamento se situa na bissetriz do ângulo obtuso, de cerca de $120^{\circ} \mathrm{e}$, portanto, ortogonal ao esforço compressivo. Resulta que todo boudin pode expor as fraturas de Riedel como nas Figuras $3 \mathrm{~A}, \mathrm{~B}$, pois são marcadores do estágio rúptil de deformação. Oportuno esclarecer que material pétreo mais competente é mais rúptil enquanto o menos competente, ou incompetente, é mais dúctil. Do ponto de vista de composição mineral, o quartzo transmite maior competência enquanto as micas transmitem mais incompetência. Os feldspatos são menos competentes do que o quartzo e menos incompetentes do que as micas. Portanto, competência se vincula com falta de clivagem, enquanto incompetência se vincula com existência de clivagem perfeita. Explica-se: a clivagem faz com que a energia vibratória ganhe mais velocidade ao

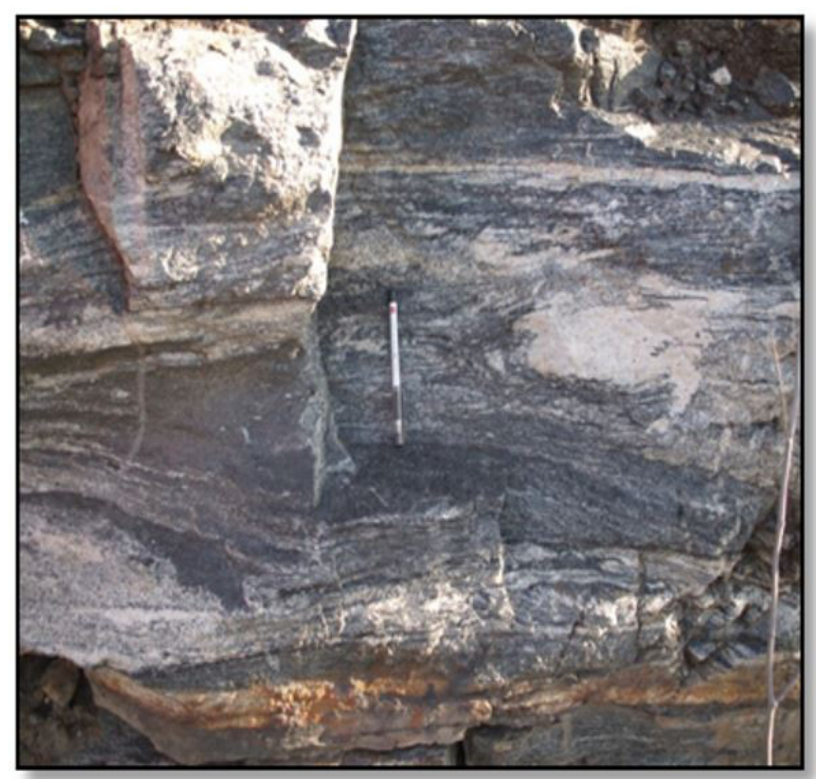

Figura I. Sigmóide.

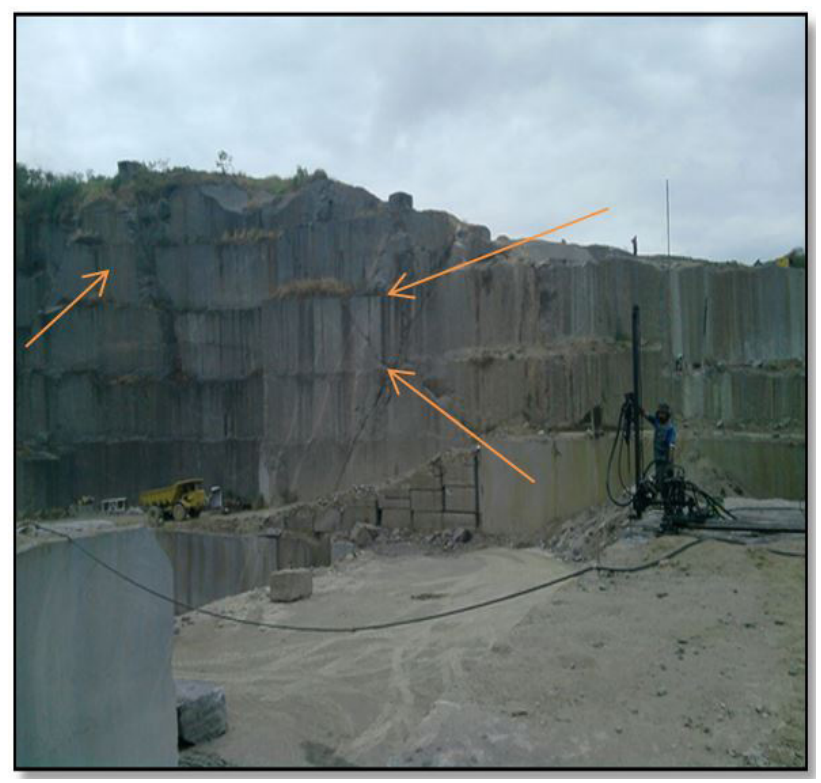

Figura 2. Fraturas de Riedel.

longo de seu plano, como no caso das micas, reduzindo as chances de fragmentação ou ruptura. Analogamente, a foliação atua na rocha, como a clivagem atua no mineral, traduzindo pois a maior ou menor competência do material rochoso. Materiais orientados são menos competentes ou mais dúcteis e os mais isotrópicos são mais competentes, mais rúpteis [3].

O principal objetivo desse estudo é a análise das feições geométrico-estruturais identificadas nos maciços rochosos utilizados para produção das rochas ornamentais denominado comercialmente, Preto São Marcos e Cappuccino. Essas rochas são explotadas respectivamente pelas empresas Top Stone Mineração e Fuji S/A Mármores e Granitos, ambas na Paraíba, como mostra a Figura 4. 


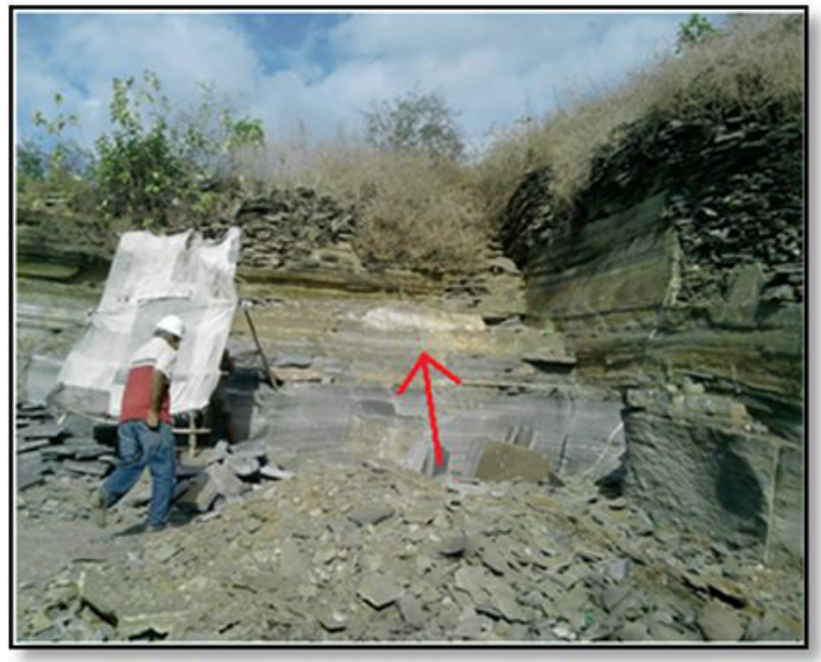

(A)

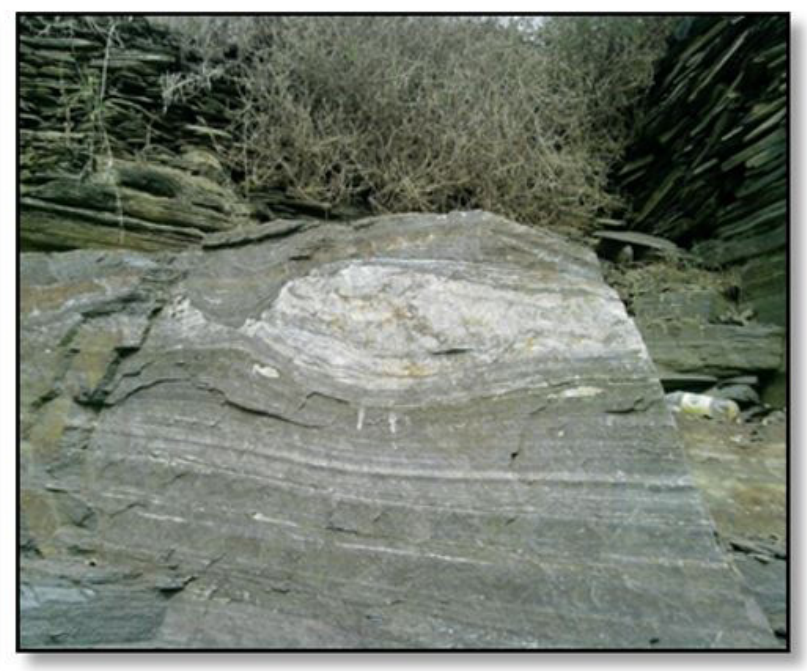

(B)

Figura 3. Boudin (A), explicitando o estágio rúptil de deformação, e sua imagem ampliada (B).

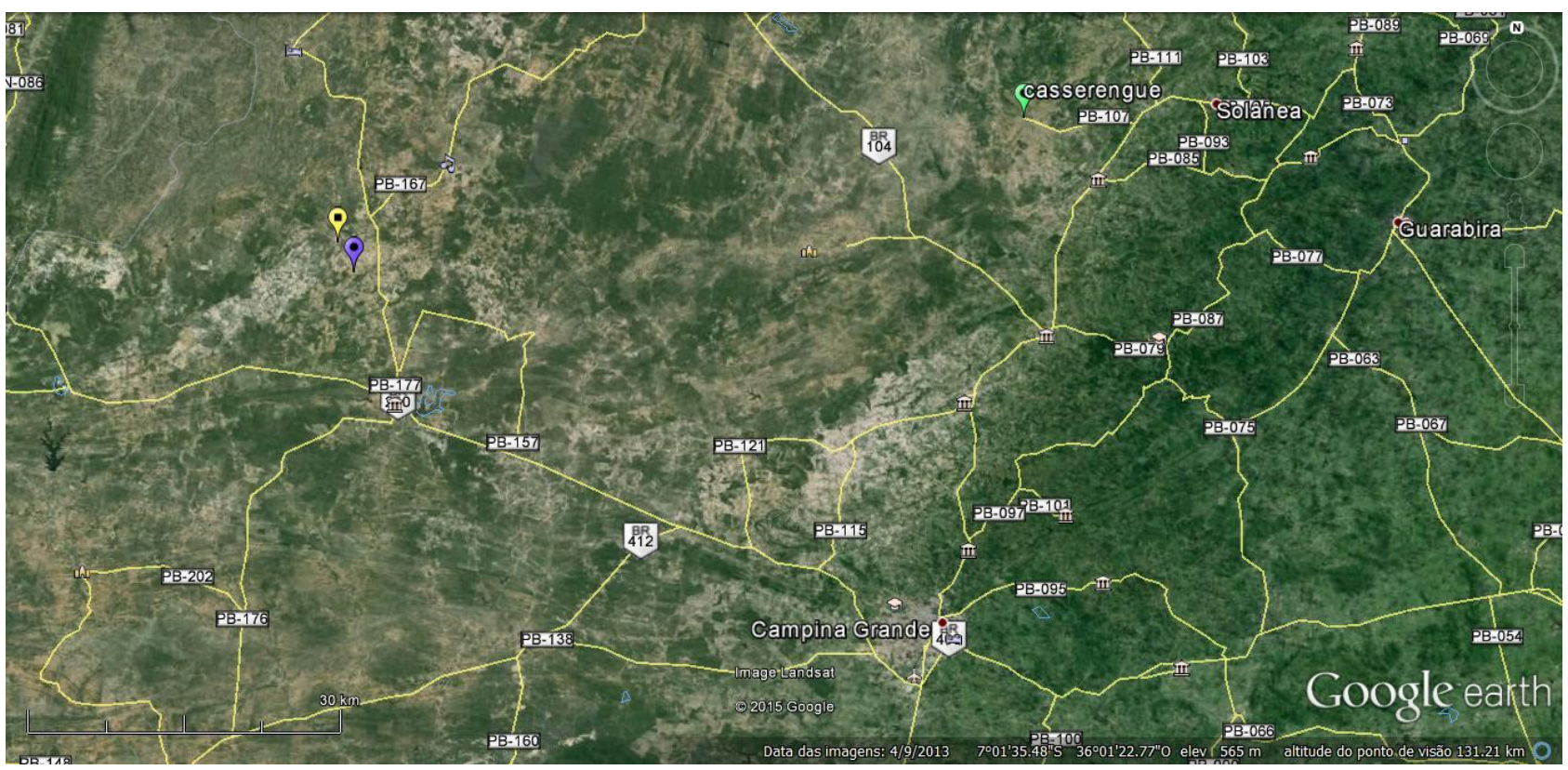

Figura 4. Mapa da localização das áreas de estudo. Fonte: Google Earth [4].

\section{CARACTERIZAÇÃO DA ÁREA DE ESTUDO}

O estudo tem como ponto de partida duas pedreiras de rochas ornamentais distintas: Top Stone Mineração, com o gabro conhecido comercialmente como Preto São Marcos, localizada no município de Casserengue; e Fuji S/A com três produtos, Exotic e Golden, no ponto azul no mapa, e o Cappuccino, ponto em amarelo no mapa, ambos na Figura 4, no Estado da Paraíba.

O granito Preto São Marcos, ponto verde no mapa, está localizado acerca de $10 \mathrm{~km}$ do município de Casserengue e a $64 \mathrm{~km}$ da cidade de Campina Grande, na Paraíba. Na pedreira, a ocorrência do material se dá na forma de matacões e maciços. A área da lavra ocorre em um pluton gabróide que ocupa $6 \mathrm{~km}^{2}$ de área. O Preto São Marcos, do ponto de vista geotectônico, corresponde a uma fração da suíte plutônica neoproterozóica ocupando parte dos terrenos São José do Campestre e Faixa Seridó, Rio Grande do Norte. Em afloramentos, o granitóide Preto São Marcos apresenta um aspecto quase homogêneo, tanto na cor como na textura, e pode ser descrito como uma rocha ígnea, de granulometria média a grossa e textura hipidiomorfica a porfirítica com fenocristais de até mais de I (um) $\mathrm{cm}$. Portanto trata-se de rocha gabróide, cuja granulação dos cristais varia deste supramilimétrica a centimétrica, desdobrando potencialidade de baixa alterabilidade, sobremodo beneficiada

Tecnol. Metal. Mater. Miner., São Paulo, 
pela presença do magnésio, dado que neutraliza ou diminui o potencial de oxidação, não raro estimulado pelo ferro. O granito pegmatóide Cappucino apresenta um domínio de plagioclásios sódicos sobre feldspatos potássicos, com porção de quartzo e lamelas de muscovita. Esses granitos pegmatoides são interpretados como pertencentes à última fase do Ciclo Brasiliano, estando associados às intrusões pegmatíticas da Província Pegmatítica da Borborema.

\section{METODOLOGIA}

O trabalho foi realizado a partir de observações de campo nas duas pedreiras tomadas como parâmetros de estudo. Consistiu em diagnóstico de campo onde foram selecionadas previamente duas áreas que apresentavam afloramento e confinamento. Uma das metodologias aplicada no trabalho foi proposta por Palmströn (1982) [5], sugerindo que, quando não se dispõe de testemunhos de sondagem, mas os traços de descontinuidades são visíveis nas superfícies de exposição de um maciço rochoso, o IQR (Índice de Qualidade da Rocha) poderá ser estimado a partir do número de descontinuidades por unidade de volume, parâmetro que pode ser determinado pela adição das frequências (número de descontinuidades por metro) obtidas para cada conjunto individual de descontinuidades ao longo de linhas de varredura normais a cada conjunto. In loco, foram feitos registros fotográficos, correspondentes a essas linhas de varredura que se define como scan face. $O$ Scan Face é um método utilizado para mapear, em detalhe, as descontinuidades presentes em maciços rochosos.
O espaçamento, ou frequência, das descontinuidades é determinado em termos da distância média entre as descontinuidades, sendo as distâncias tomadas geralmente ao longo de linhas de varredura complementados por macro análise dos maciços, como pode ser visto na Tabela I, sempre através de observação visual direta dos mesmos.

\section{RESULTADOS E DISCUSSÃO}

O presente trabalho demonstrou o comportamento das tensões sobre maciços rochosos nos diferentes ambientes, seja confinado ou aflorante, em pedreiras de rochas ornamentais, ocorrentes em ambientes confinados (Granitóide Preto São Marcos) e aflorante (Golden, Exotic e Cappuccino). Análise feita em campo permitiu observar que as jazidas em ambiente confinado apresentaram tensões de alivio com frequência de fraturamento superior a I/metro caracterizando o estágio de deformação do maciço rochoso como frágil/dúctil, ocasionando, todavia, dificuldades para se obter o bloco de partição, cujas dimensões devem ser compatíveis com aquelas do tear multi-lâminas ou multifios. Observa-se também a ocorrência das jazidas em baixo relevo; e como resultado, o confinamento original, ao ser removido, faz surgir fraturas de alívio após a abertura da face livre, como mostram as Figuras 5 e 6.

No caso de jazidas em ambiente aflorante foi diagnosticada a presença de fraturas de alivio com frequência inferior a I/metro, conforme a Figura 7. Este fato favorece a uma otimização superior do bloco de partição; menos fraturas no maciço possibilita a extração de blocos maiores,

Tabela I. Dados coletados para visualização da linha de varredura contendo os principais parâmetros analisados no maciço

\begin{tabular}{|c|c|c|c|c|c|c|}
\hline Ponto (m) & Fratura & Direção (Az) & Mergulho (Az) & Distância (cm) & Frequência & $\begin{array}{c}\text { Estágio } \\
\text { Reológico }\end{array}$ \\
\hline \multirow{6}{*}{$0-30$} & I & $73 / 253 \mathrm{Az}$ & $54 / 163 \mathrm{Az}$ & $\geq 5 \mathrm{~cm}$ & $4 / m$ & Frágil Rúptil \\
\hline & 2 & $75 / 257 \mathrm{Az}$ & I5/347 Az & $\geq 20 \mathrm{~cm}$ & $3 / \mathrm{m}$ & Frágil Dúctil \\
\hline & 3 & $40 / 220 \mathrm{Az}$ & $22 / 310 \mathrm{Az}$ & $\geq 10 \mathrm{~cm}$ & $4 / m$ & Frágil Rúptil \\
\hline & 4 & $160 / 340 \mathrm{Az}$ & $30 / 250 \mathrm{Az}$ & $\geq 15 \mathrm{~cm}$ & $2 / m$ & Frágil Dúctil \\
\hline & 5 & $35 / 215 \mathrm{Az}$ & $69 / 125 \mathrm{Az}$ & $\geq 5 \mathrm{~cm}$ & $4 / m$ & Frágil Rúptil \\
\hline & 6 & $10 / 190 \mathrm{Az}$ & $67 / 280 \mathrm{Az}$ & $\geq 20 \mathrm{~cm}$ & $3 / \mathrm{m}$ & Frágil Dúctil \\
\hline \multirow{10}{*}{$30-60$} & 7 & $65 / 245 \mathrm{Az}$ & $50 / 155 \mathrm{Az}$ & $\geq 15 \mathrm{~cm}$ & $2 / \mathrm{m}$ & Frágil Dúctil \\
\hline & 8 & I65/345 Az & $70 / 255 \mathrm{Az}$ & $\geq 10 \mathrm{~cm}$ & $4 / m$ & Frágil Rúptil \\
\hline & 9 & $70 / 250 \mathrm{Az}$ & $50 / 160 \mathrm{Az}$ & $\geq 20 \mathrm{~cm}$ & $3 / \mathrm{m}$ & Frágil Dúctil \\
\hline & 10 & $85 / 265 \mathrm{Az}$ & $50 / 175 \mathrm{Az}$ & $\geq 10 \mathrm{~cm}$ & $6 / \mathrm{m}$ & Frágil Rúptil \\
\hline & II & I65/345 Az & $70 / 255 \mathrm{Az}$ & $\geq 5 \mathrm{~cm}$ & $4 / m$ & Frágil Rúptil \\
\hline & 12 & I50/330 Az & $30 / 240 \mathrm{Az}$ & $\geq 10 \mathrm{~cm}$ & $4 / m$ & Frágil Rúptil \\
\hline & 13 & $105 / 295 \mathrm{Az}$ & $25 / 205 \mathrm{Az}$ & $\geq 10 \mathrm{~cm}$ & $5 / \mathrm{m}$ & Frágil Rúptil \\
\hline & 14 & $160 / 340 \mathrm{Az}$ & 73/70 Az & $\geq 20 \mathrm{~cm}$ & $3 / \mathrm{m}$ & Frágil Dúctil \\
\hline & 15 & $50 / 230 \mathrm{Az}$ & $59 / 320 \mathrm{Az}$ & $\geq 5 \mathrm{~cm}$ & $4 / m$ & Frágil Rúptil \\
\hline & 16 & $20 / 200 \mathrm{Az}$ & $84 / 290 \mathrm{Az}$ & $\geq 5 \mathrm{~cm}$ & $4 / m$ & Frágil Rúptil \\
\hline \multirow{4}{*}{$60-72$} & 17 & $60 / 240 \mathrm{Az}$ & $57 / 150 \mathrm{Az}$ & $\geq 10 \mathrm{~cm}$ & $5 / \mathrm{m}$ & Frágil Rúptil \\
\hline & 18 & $65 / 245 \mathrm{Az}$ & $82 / 155 \mathrm{Az}$ & $\geq 10 \mathrm{~cm}$ & $6 / \mathrm{m}$ & Frágil Rúptil \\
\hline & 19 & I55/335 Az & $60 / 245 \mathrm{Az}$ & $\geq 10 \mathrm{~cm}$ & $5 / \mathrm{m}$ & Frágil Rúptil \\
\hline & 20 & $180 / 360 \mathrm{Az}$ & vertical & $\geq 5 \mathrm{~cm}$ & $7 / \mathrm{m}$ & Frágil Rúptil \\
\hline
\end{tabular}




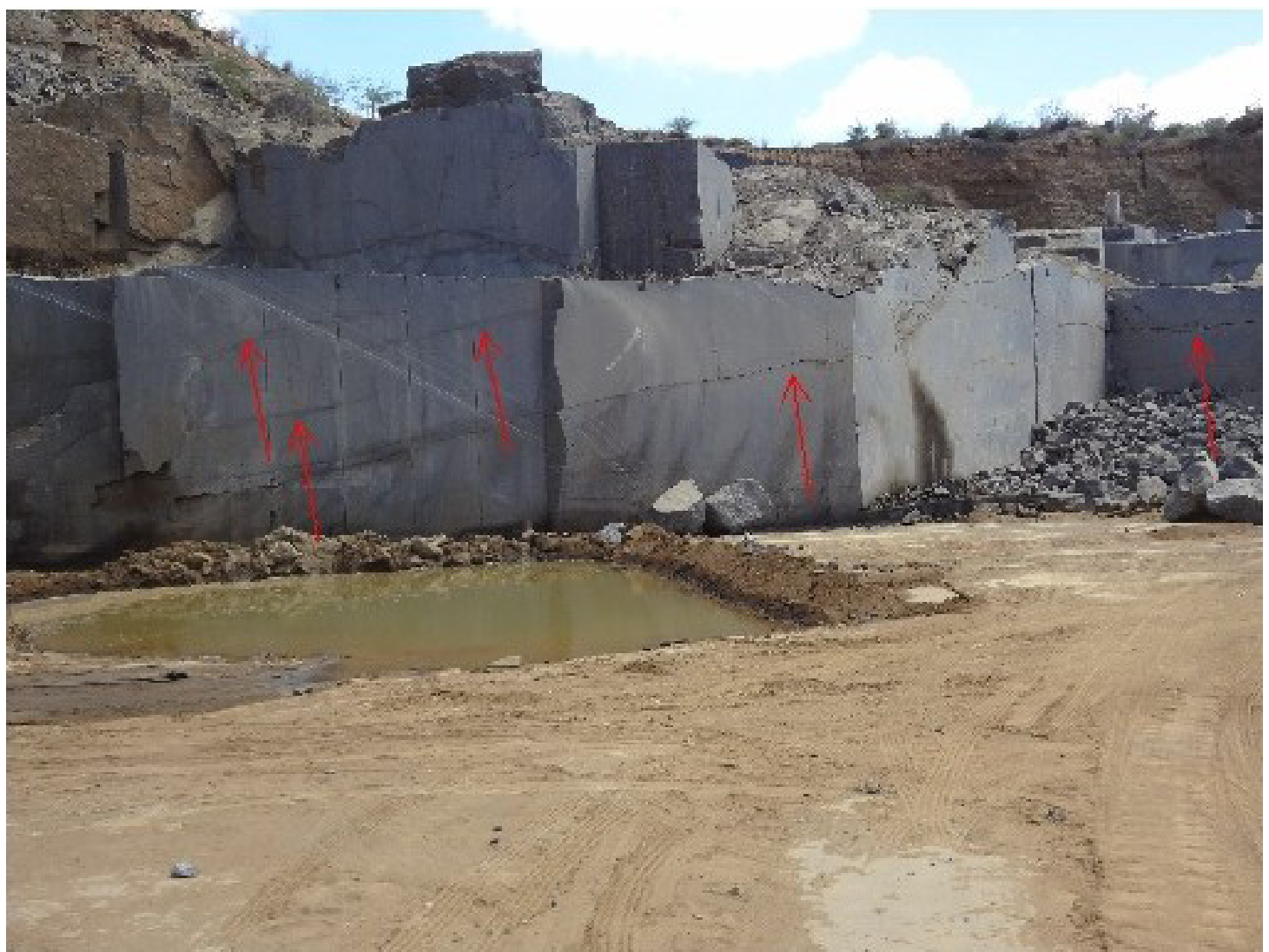

Figura 5. Frente de Lavra Sul da Pedreira Top Stone, Preto São Marcos, município de Cassenregue-PB.

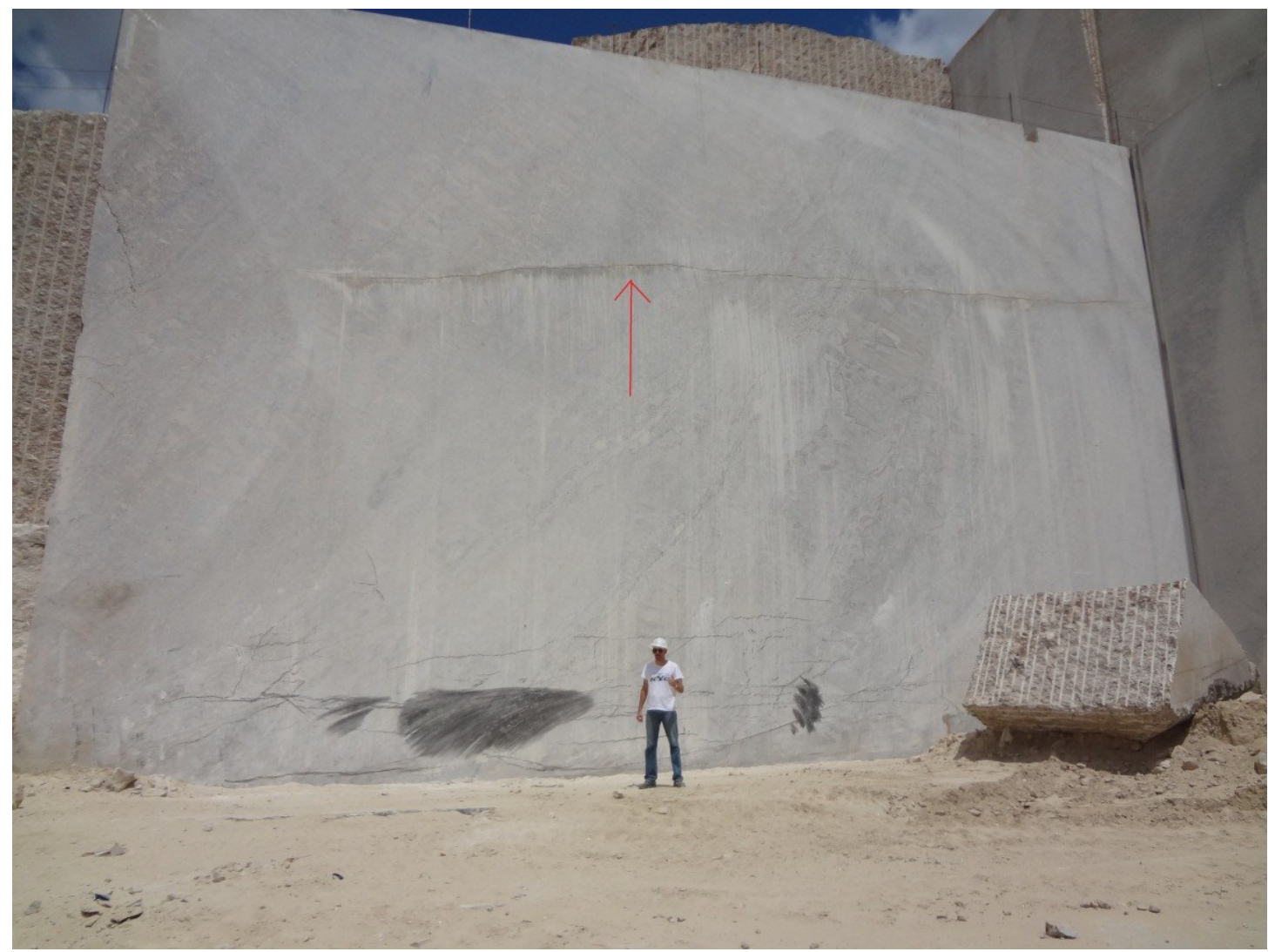

Figura 6. Indicação de fratura de alivio na frente de lavra, pedreira Fuji, Rocha ornamental tipo Cappuccino.

Tecnol. Metal. Mater. Miner., São Paulo, 
compatíveis com as dimensões dos teares, melhorando a produtividade das chapas.

Observa-se uma maior susceptibilidade de exposição das fraturas na face aberta com fio diamantado, devido ao alívio das tensões no maciço que ocorre de maneira instantânea, ao contrário do que ocorre nas faces abertas com a técnica da perfuração contínua ou pré-corte com massa expansiva, onde teremos um tempo maior para o alívio das tensões no maciço, como mostra a Figura 8.

Observa-se também, uma zona de deformação composta por um arranjo de pequenas falhas. Estas são classificadas com base na atitude e sentido do deslocamento em relação à tendência geral da zona de falhas de rejeito direcional como mostra a Figura 9.

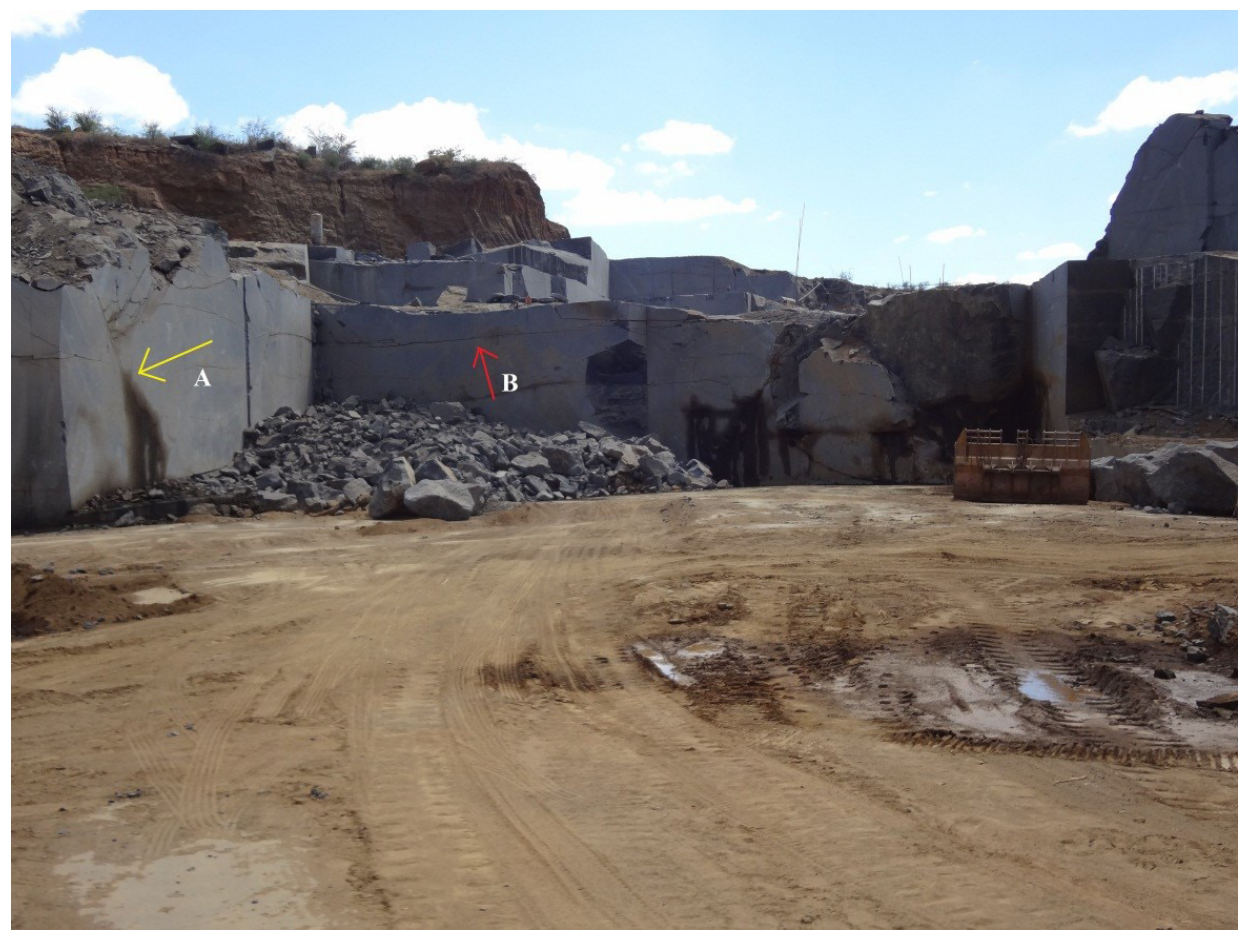

Figura 7. (A) indicação de fratura de cisalhamento; (B) indicação fratura de alívio. Frente de lavra sul na pedreira Top Stone.

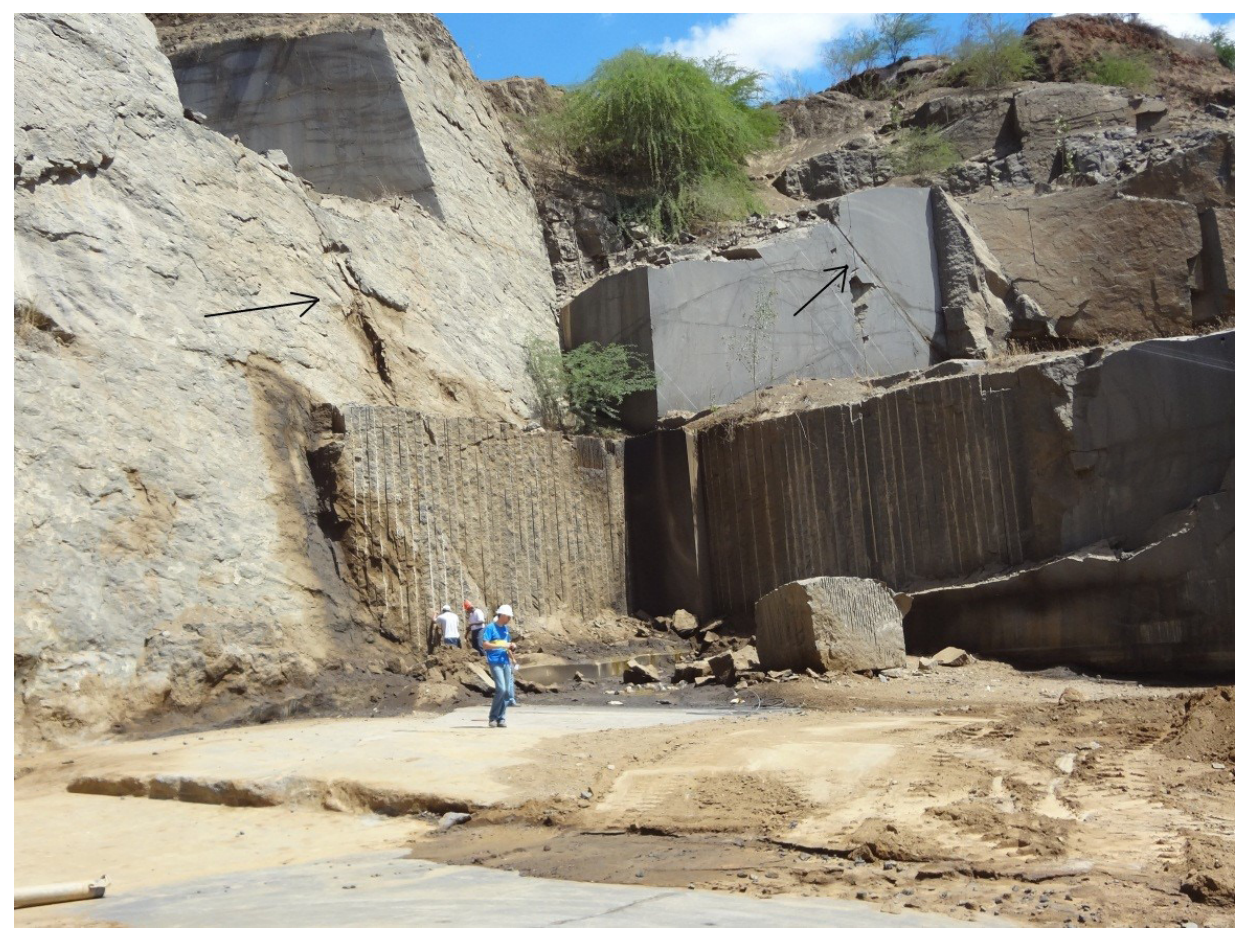

Figura 8. Indicação de fratura de cisalhamento na frente de lavra sul na pedreira Top Stone. 


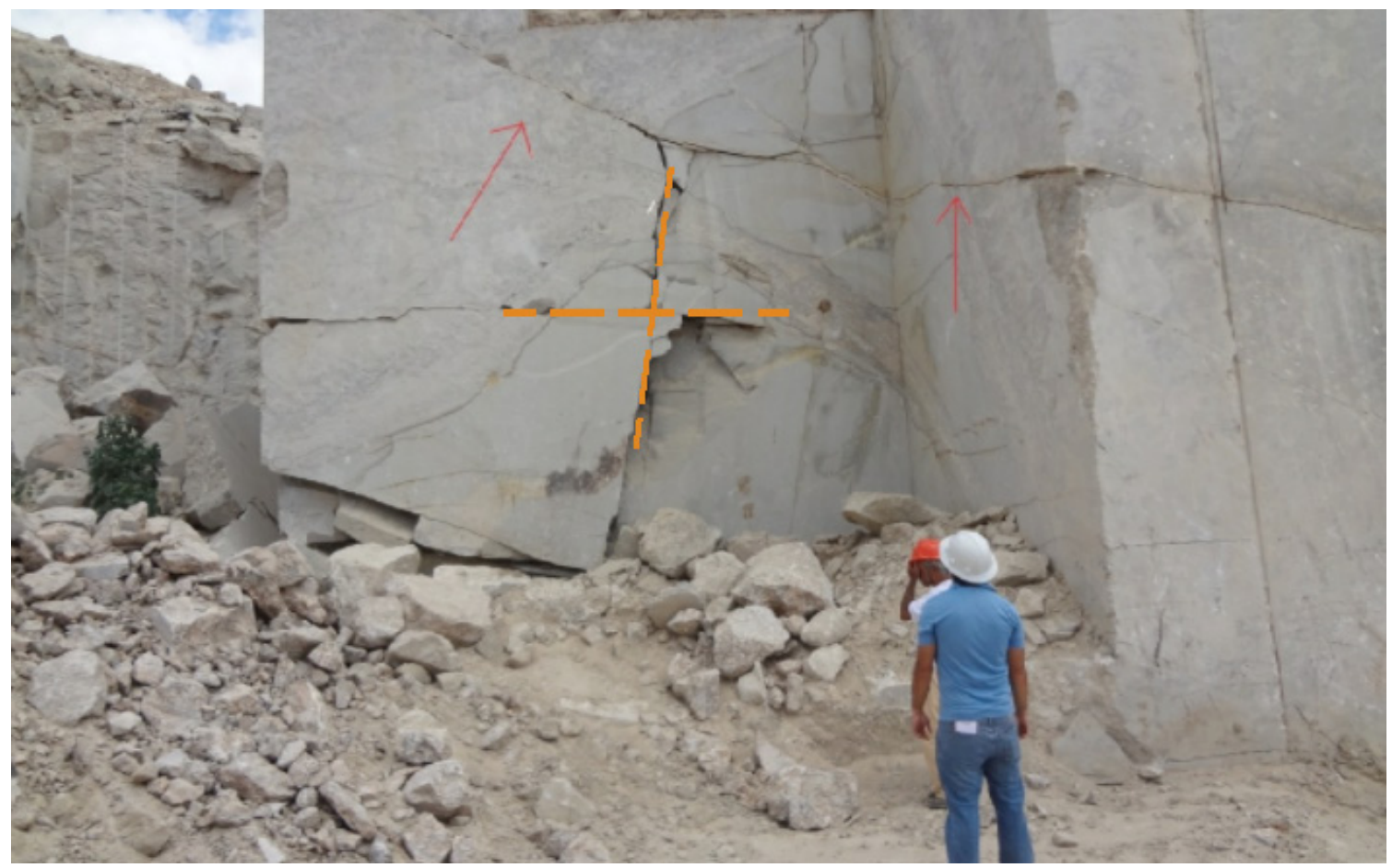

Figura 9. Indicação de fraturas de cisalhamento tipo Riedel.

A lavra a céu aberto é um tipo de método aplicado à mineração quando há baixa relação estéril/minério, caracterizando-se, adicionalmente, por impulsionar a sua produtividade em áreas de afloramento do maciço rochoso [6]. No trabalho em pedreiras, que se relacionam com o método de lavra a céu aberto, destacam-se certos estudos como: i. orientação das bancadas da pedreira, ou de sua face livre concordante com a superfície alongante da rocha, para otimização da frente de lavra; ii. área a ser explorada para otimização da malha utilizada, para o desmonte de rocha com explosivos; iii. segurança traduzida pela acessibilidade dos transportes utilizados na pedreira e possíveis rotas de fuga em caso de acidentes; iv. estudo das propriedades geomecânicas da rocha, que terá influência direta na seleção do método de lavra apropriado na extração e na seleção dos equipamentos a serem utilizados, e na qualidade do produto extraído para fase de beneficiamento [7].

\section{CONSIDERAÇÕES FINAIS}

Na produção de rochas ornamentais é determinante que as frequências de fraturas sejam inferiores a $\mathrm{I} / \mathrm{m}$ para viabilizar a produção de blocos após o desmonte da prancha.
Entretanto no caso do Preto São Marcos, análise feita em campo permitiu observar que as jazidas em ambiente confinado apresentaram tensões de alivio com frequência de fraturamento superior a $\mathrm{l} /$ metro caracterizando o estágio de deformação do maciço rochoso como frágil/dúctil, ocasionando, todavia, dificuldades para se obter o bloco de partição. É verdade, contudo, que há possibilidade da aplicação de técnica de resinamento de blocos o que melhora - beneficiamento das chapas, quando o material pétreo ornamental, apesar de apresentar comportamento frágil, tem grande aceitação no mercado Este é caso de materiais como os pegmatóides cuja textura atrai as atenções dos profissionais da área de Arquitetura e Design. Igualmente, a determinação do bloco de partição é indispensável para uma melhor exploração de cada frente. Por fim, a técnica de utilização do fio diamantado para abertura de face livre vem melhorando bastante durante a exploração da rocha ornamental, mas pode ser observada na documentação fotográfica apresentada, sua maior susceptibilidade para expor fraturas de alívio e de distensão [8].

\section{REFERÊNCIAS}

I Teixeira W, Fairchild TR, Toledo MCM, Taioli F. Decifrando a terra. 2. ed. São Paulo: Companhia Editora Nacional; 2009. $623 \mathrm{p}$.

2 Fossen H. Geologia estrutural. São Paulo: Ofinica de texto; 20I2. vol. I.

Tecnol. Metal. Mater. Miner., São Paulo, 
Araújo et al.

3 Beer PF, Johnston ER Jr. Resistência dos materiais. 3. ed. São Paulo: Editora Pearson Makron Books; 1995.1255 p.

4 Google Earth [página da internet]. 2015 [acesso em 9 ago. 2015]. Disponível em: https://www.google.com.br/intl/ pt-PT/earth/

5 Araújo A. Marcadores de deformação e estágio de deformação com determinação do bloco de partição em pedreiras na região metropolitana do recife [dissertação de mestrado]. Recife: Centro de Tecnologia e Geociência, Universidade Federal de Pernambuco; 2014.

6 Fiori AP. Fundamentos de mecânica dos solos e das rochas: aplicações na estabilidade de taludes. 2. ed. Paraná: Editora UFPR; 2009. p. 438-439.

7 Matta PM. Prospecção e pesquisa de rochas ornamentais: uma contribuição à produção limpa. In: Anais do $4^{\circ}$ Simpósio de Rochas Ornamentais do Nordeste; 2003; Fortaleza, Brasil. Fortaleza: CETEM/SBG; 2003. p. 2 I-32.

8 Menezes GR. Curso de especialização em tecnologia e valorização em rochas ornamentais: tecnologias de lavras em maciços rochosos [monografia]. Rio de Janeiro: Universidade Federal do Rio de Janeiro; 2005.

Recebido em: 5 Jan. 2016

Aceito em: 23 Maio 2016 